\title{
A REFLECTION ON THE ROLE OF ICP-MS IN PROTEOMICS: UPDATE AND FUTURE PERSPECTIVE
}

Francisco CALDERÓN-CELIS, Jorge RUIZ ENCINAR*

Department of Physical and Analytical Chemistry, University of Oviedo, Spain

"Corresponding author:

Dr. Jorge Ruiz Encinar

Department of Physical and Analytical Chemistry

University of Oviedo, Julián Clavería 8, 33006 Oviedo, Spain

Email: ruizjorge@uniovi.es

Telephone: +34 985103069 


\section{ABSTRACT}

Mass spectrometry is the technique of reference for the identification and quantification of proteins. Whereas ESI and MALDI ionization sources are inherently not quantitative being highly influenced by the chemical nature of the analyte and the matrix, ICP-MS uses a hard ionization source that destroys proteins into its atoms and measures the elemental signal, which is independent of its chemical environment. As a consequence, ICP-MS turns up as an excellent technique for the screening, mapping and quantification of peptides and proteins in a sample through elemental detection (any element but $\mathrm{C}, \mathrm{H}, \mathrm{N}$, or $\mathrm{O}$ ) once they have been previously separated by chromatography. In this time, great efforts have been put in developing instrumentation and new methodologies that enable a better, more efficient, and more useful analysis of proteins with ICPMS. Moreover, quantitative capabilities but lack of molecular information of ICP has led to a synergic relationship both with identifying capabilities of ESI-MS, or the use of protein-specific antibodies carrying an elemental label.

\section{Journal Significance}

We are delighted to participate in this special issue and have the chance to congratulate Journal of Proteomics for its $10^{\text {th }}$ Anniversary, and wish for many further successful anniversaries. During this last decade, Journal of Proteomics has been a clear promotor of works integrating ICP-MS for proteomics analysis. In fact, already in 2009, a review was published by invitation of the editor in chief focused on the established and potential role of ICP-MS in different areas of the proteomics analysis at the time: "The emerging role of ICP-MS in proteomics" [1]. Even though ICP-MS is not fully known or acknowledged in the proteomics world yet, its impact was significant as demonstrated by the really high interest in such publication (over 150 citations). Since then, several excellent papers relating to ICP-MS applications in proteomics have been published in this journal. Following the trend, we expect through this personal view of the current standing of ICP-MS in proteomics to enlighten the readers of Journal of Proteomics with a vision of the full present and future potential of ICP-MS in proteomics.

\section{Abbreviations}

AQUA: Absolute Quantification, MS: Mass Spectrometry, ESI: Electrospray Ionization, MALDI: Matrix-Assisted Laser Dissociation/Ionization, ICP-MS: Inductively Coupled Plasma Mass Spectrometry, ToF: Time of Flight, HPLC: High-Performance Liquid Chromatography, HILIC: Hydrophilic Interaction Liquid Chromatography, SEC: Size Exclusion Chromatography, SIL: StableIsotope Labeled, PTM: Post-Translational Modification. 


\section{The context of ICP-MS in Proteomics}

Inductively Coupled Plasma Mass Spectrometry (ICP-MS) is a technique within the mass spectrometry battery that consists on the use of a hard ionization source (argon plasma at atmospheric pressure) to break down any molecule into its constituent atoms, which are then ionized in that plasma. As any mass spectrometry technique, these ionized atoms are guided through or filtered by the mass analyzer on basis of their $\mathrm{m} / \mathrm{z}$ ratio, until they reach the detector. The distinctive feature of this elemental technique is that the element ionization is independent of the chemical structure of the compound containing it. That is particularly advantageous for quantitative purposes, since there is no need to use standards specific to each analyte, as any compound that contains the target detectable element (any but $\mathrm{C}, \mathrm{H}, \mathrm{N}$, and $\mathrm{O}$, because ICP plasma works at atmospheric pressure) is useful as quantification standard (e.g., inorganic salts) [2,3].

Nonetheless, this asset of ICP-MS is at the same time its limitation, since no structural information or identification can be obtained from an atomized peptide or protein. Therefore, the molar ratio element:protein is mandatory to translate the elemental signal from the target compound into peptide/protein quantification. That is why instrumental and methodological advances towards the complementarity between ICP-MS and molecular mass spectrometry techniques (mainly ESI) are essential to strengthen its role in protein analysis [4]. This integrated ICP-MS and ESI-MS approach was feasible with the development of micro-nebulizers [5] and sample interfaces [6] that made compatible n/ $\mu$-LC with ICP-MS [7]. As a result, required sample volumes to be injected in ICP-MS analysis were dramatically reduced (now in the range of $n L-\mu L$ volumes), and also any potential nebulization or sample transport effects in the ICP nebulization chamber [8] were eliminated. Last but not least, ICP-MS became fully compatible with the organic solvents typically used in protein chromatography (i.e., reversed-phase or HILIC).

Still, the main Achilles' heel in ICP-MS-based quantification is to be solved. That is, the complete separation of all species containing the detected element. Because signal is elemental, ICP-MS cannot discriminate the molecules of origin of that element, and therefore all detected species in the sample have to be separated first in order to have an accurate correlation between element and peptide/protein. Despite ICP-MS versatility supports an easy coupling to LC and CE separation strategies, most quantitative applications with ICP-MS in proteomics are still restrained to peptide/protein standards, and in few cases medium-complex real samples have been successfully analyzed and quantified with ICP-MS. However, due to the lack of resolution of current separation methods, the possibility to analyze complex samples at the level of a full proteome is still out of the picture, even if using state of the art multidimensional chromatographic systems. 
In this context, the use of the corresponding antibody, specific of the protein of interest, is a useful alternative to fish and isolate the target protein within the complex sample. Additionally, such specific antibody could carry an element label to make the target protein detectable by ICP-MS. Such combination of immunoassays with ICP-MS is becoming attractive due to its potential coupling with ablation techniques enabling "target" protein bio-imaging through the detection of the labelled element.

Figure 1 exemplifies the different strategies that can be addressed nowadays in proteomics analysis with ICP-MS.

\section{The Paradigm evolved from Metallomics to Proteomics}

After the introduction of ICP-MS in the $80 \mathrm{~s}$, a great number of potential applications were foreseen in the fields of proteomics $[9,10]$. However, main application at first were focused on the analysis of metalloproteins, through the ICP-MS detection of the coordinated metal $(\mathrm{Fe}, \mathrm{Zn}, \mathrm{Cu}$, etc.), in order to study the interaction of the metal with the protein, and its influence on the biochemical processes of the organism [11,12]. The possibility to detect several elements (and isotopes) with ICP-MS is extremely useful to selectively screen species that contain one or more target elements, even in complex samples. Moreover, it may serve as preparative step, using a first SEC-ICP-MS screening analysis to isolate or fractionate the sample of interest, for a later analysis with ESI-MS or ICP-MS [13]. In fact, this kind of strategy has proved useful for the screening of the distribution of a certain element (e.g., Se) along the proteins of a sample [14] and its subsequent purification after removal of highly-abundant interfering proteins [15].

However, application of such analysis to quantitative proteomics is severely limited because metal-protein bonding is labile, so it can be disrupted under certain circumstances during pre-ICPMS separation. This is the case when using organic modifiers $(\mathrm{MeCN}, \mathrm{MeOH}$, etc.) for typical reversed-phase or HILIC chromatographic gradients, and even with less "aggressive" separations such as CE, SEC or ion exchange chromatography [16]. Additionally, in order to translate metal information into protein concentration it is required to know the stoichiometry metal:protein. In this regard, such determination can be done through the simultaneous detection of the target element together with sulfur, which is present in the protein moiety [13,17], although most of the times the existing metal-to-protein complexes are already well known.

Interestingly, most metallic elements coordinated to proteins have more than one stable isotope, so that elemental quantification can be directly approached through isotope dilution analysis. Instead of an analogous counterpart of the peptide or protein labeled with a stable isotope as in SIL-based 
molecular mass spectrometry approaches [18], in most ICP-MS-based quantifications a generic inorganic compound enriched in an isotope of the target element (one isotope for each element) can be used as simple standard added continuously post-column [19].

Of course, stoichiometry determination through simultaneous detection with sulfur is valid both in the case of proteins that coordinate metals, and/or those that carry one or more chemical modifications, e.g. phosphoproteins (P/S), selenoproteins (Se/S), or As-binding proteins (As/S). Statistically, in eukaryotic proteins every 20 amino acids there is at least one methionine or cysteine, so that vast majority of polipeptides and proteins contain sulfur [20]. Therefore, experimental ratio element:sulfur can be translated into molar ratio element:protein if the amino acid sequence is known or determined. Unfortunately, sulfur detection with ICP-MS was severely hindered using regular quadrupole- or sector field-based ICP-MS instruments.

One of the main focus of this kind of analysis has been the quantitative characterization of peptides and proteins phosphorylation. In 2001, Mathias Wind and coworkers already stated the potential of ICP-MS for the identification of protein phosphosites and determination of proteins phosphorylation degree in tryptic digest with ICP-MS and ESI-MS [7,21]. During this time, different modifications of this approach have arose, using organic or inorganic phosphorous standards to quantify phosphorylation degree in peptides [22,23] and proteins [24]. In fact, great precision and accuracy achieved in some of those developed strategies [22] enabled the differential characterization of phosphorylation dynamics of several peptides when subjected to phosphatase over time [25], and proved useful to characterize peptide recovery in $\mathrm{TiO}_{2}$ enrichment cartridges [26], used for affinity-based isolation/purification of phosphopeptides in bottom-up MS strategies [27].

However, phosphopeptides/proteins analysis with LC-ICP-MS has a critical practical limitation. That is the influence of organic modifiers (LC gradients) in the elements ionization efficiency [26]. This had to be taken into account when determining phosphorylation degree in a protein, usually by relating the phosphorous quantity obtained from ICP-MS detection with the known (or determined) protein quantity. In the case of directly determination through $\mathrm{P} / \mathrm{S}$ ratio, this situation becomes more severe, not just because of limitations in sulfur detection, but due to the fact that variations in sensitivity affect much differently to $\mathrm{P}$ and S. Given that phosphorous is a monoisotopic element, isotope dilution analysis cannot be used to address correction of such signal variations, which dropsoff quality of quantitative results. In consequence, several strategies has been proposed: mathematical corrections based on the analysis of $\mathrm{P}$ and $\mathrm{S}$ standards at the LC conditions at which the peptides eluted [21]; addition of a post-column flow of an aquo-organic solution to screen effect 
of LC gradients [22]; or the use of a secondary chromatograph instrument that provides a second flow with inverse composition to that of the chromatographic separation, providing a constant phosphorous signal along a RP-LC analysis [23].

Biological importance of selenoproteins have also resulted in several methodologies for detecting and quantifying selenium present in peptides and proteins. For example, Giusti and coworkers were able to quantify peptides containing selenomethionine from a tryptic digest of a selenoprotein using parallel nLC-ESI-MS for identification of such peptides (Se:peptide stoichiometry) [28]. Interestingly, this strategy proved useful to characterize efficiency of tryptic digestion procedure. On the other hand, $\mathrm{Xu}$ and coworkers carried out determination of the concentration and distribution of selenium in several proteins in human plasma, and selenium content in those proteins of known amino acid sequence [29].

\section{Sulfur marked the turning point in quantitative proteomics}

Although sulfur detection is useful to study stoichiometries heteroatom:protein, its greatest relevance would actually be the quantification of proteins through the determination of their constituent sulfur with ICP-MS [30,31]. Given that sulfur is statistically present in all proteins, Sbased protein quantification is applicable to any protein, and not solely to a limited number of them that contain a specific heteroatom (e.g., $\mathrm{P}$ or Se). That is, capability of ICP-MS to detect sulfur makes of it a generic and quantitative detector of proteins. However, such direct analysis has been traditionally hampered. First, because unlike in the case of phospho- or selenoprotein analysis in which only a certain number of proteins need to be separated, in this case complete separation of all proteins in the sample is required. Moreover, low ionization efficiency and spectral interferences (e.g. ${ }^{16} \mathrm{O}^{16} \mathrm{O}^{+},{ }^{14} \mathrm{~N}^{18} \mathrm{O}^{+},{ }^{15} \mathrm{~N}^{16} \mathrm{OH}^{+}$over ${ }^{32} \mathrm{~S}$ ) in ICP-MS detection of sulfur result in much lower sensitivity for sulfur in comparison with other elements, thus being required higher amounts of proteins in order to be properly detected [32], which is a limiting factor in biological analysis.

As an alternative, protein quantification has been addressed through the labeling of peptides and proteins with heteroatom-carrying tags. In this regard, different approaches have been used, such as the specific iodination of tyrosine residues for peptide quantification through iodine ICP-MS detection [33], or the use of lutetium-DTPA tags that bound to N-term and Lys chains of peptides, providing peptide quantification via inorganic isotope dilution analysis [34]. The concept of such tagging strategies has been also extended to the quantification of PTMs, like phosphorylation, e.g., by means of specifically tagging phosphorylated amino acids (pY, pS, pT) with Gallium-tags, resulting in extremely high sensitivity [35]. All these strategies are limited however by the stringent 
demands of specificity and efficiency of the labeling, so they are more appropriate to be used at the peptide level, especially in those cases that peptides do not contain any ICP-detectable element (e.g., $\mathrm{S}, \mathrm{P}$, or $\mathrm{Se})$.

The whole situation changed in 2012, when ICP-MS tandem analyzer with a set of two quadrupoles, one before and one after the collision/reaction cell, was firstly introduced [36]. This ICP-MS/MS configuration makes use of the $1 \mathrm{Da}$ selectivity in each quadrupole, resulting in bettercontrolled cell processes, and hence more efficient removal of spectral interferences in the detection of highly-interfered elements such as phosphorous and especially, sulfur [37]. Briefly in the case of sulfur, first quadrupole (Q1) selects major sulfur isotope at $\mathrm{m} / \mathrm{z} 32$ and its polyatomic isobaric interferences. Reaction with $\mathrm{O}_{2}$ in the cell separates analyte and interferences by shifting exclusively sulfur to a new product ion mass $\left(\mathrm{m} / \mathrm{z}=48,{ }^{32} \mathrm{~S}^{16} \mathrm{O}^{+}\right)$because reaction rate with $\mathrm{O}_{2}$ is much than for the polyatomic interferences. This leads to interference-free detection after setting the second quadrupole $(\mathrm{Q} 2)$ at 16 mass units higher than Q1. In fact, detection limits in comparison to single quadrupole or high-resolution ICP instruments for the detection of sulfur in proteic species improved more than one order of magnitude [36]. Such low sulfur detection limits (c.a. 15 fmol sulfur) translate into very small protein requirements, at the low fmol level of protein (considering a medium size protein containing ca. 10 sulfur atoms). It is therefore expected that this instrumentation may result in a turning point of ICP-MS in life sciences.

Still, to that point, quantitative proteomics with ICP-MS had been mainly limited to the peptide level, because of the widely known concern of chromatographic recovery (Figure 2). It is important to note here that absolute quantification provided by ICP-MS and using generic standards rests on the principle of full analyte recovery from the column. During the LC or CE analysis, intact proteins can be pseudo-permanently retained in the column or capillary $[7,17]$, resulting in a non-complete elution of the protein amount injected. As a result, quantitative results are biased by such incomplete recovery, which also depends not only on the nature of the separation but on the protein itself. Thus, in the case of protein quantification, a quantitative or controlled (this requires specific protein standards) recovery is a must [38]. In the case of peptides, however, this problem is not as frequent and recoveries are usually close to $100 \%$ [28]. Yet, such analysis has other inherent limitations (as schemed in Figure 2), such as the dimensional increase of the sample complexity, as a consequence of the higher number of species that contain the detected element when one single protein is digested into several peptides.

All these developments and considerations for ICP-MS protein analysis were eventually taken into account, put together and improved in order to accomplish absolute quantification of intact 
proteins [38]: (i) the use of micro-reversed phase chromatography to provide high-resolution separation of proteins in the sample and compatibility or organic modifiers with ICP source, and $\sim 1$ $\mu \mathrm{L}$ sample volume injected; (ii) the use of ICP-MS/MS as detector enabling the low-fmol detection of sulfur present in the assayed proteins; (iii) novel chromatographic packing in micro-flow columns that provide quantitative recoveries for intact proteins [39]; (iv) isotope dilution analysis for accurate and precise S-based protein quantification using non-specific quantification standards; (v) use of high-resolution ESI-MS instrumentation in parallel capable of carrying out intact protein identification. This strategy was demonstrated in the absolute quantitative characterization of real samples (snake venoms, which contain tens of proteic species) making complementary use of $\mu \mathrm{LC}$ ICP-MS/MS for sulfur-based quantification, and $\mu$ LC-ESI-MS for identification of intact proteoforms based on accurate mass determination (resorting to MS/MS proteomics data and data bases) and amino acid sequencing [40].

To this point ICP-MS demonstrated useful integration in proteomics, and especially top-down platforms. Yet, its quantitative capabilities were constrained in the case of multi-elemental quantitative analysis. In the case of multi-isotopic elements, isotope dilution analysis can be used, resorting to the use of extra instrumental set-up and isotopically-enriched reagents for each element though. In the case of the analysis of monoisotopic elements (mainly P or As), however, it was necessary to use alternative quantitative strategies such as mathematical corrections or complex instrumental configurations which moreover limit experimental conditions and capacity. Alternatively, a new methodology based on the previously described strategy [38] has been developed just recently [41]. It consists on an instrumental modification at the ICP-MS level, and thus can be easily implemented, that does not require from additional instrumental set-ups after the chromatographic separation nor isotopically-enriched reagents [41]. This strategy enables simultaneous quantitative analysis of elements of interest in proteomics such as S, P, Se and I, and elements that are gaining relevance such as As [42]. Moreover, this approach resulted in a significant increase of sensitivity in the detection of these elements in regards to isotope dilution analysis. Finally, it has been successfully applied to the absolute quantification of protein species in real samples, demonstrating its easier combination with LC-ESI-MS analysis and thus its potential as integrative complementary tool in top-down proteomics workflows.

Of course, there is still plenty of room for improvement. It is undeniable that new approaches and instrumental developments in terms of chromatography and intact and top-down protein analysis with ESI-MS-based instruments with better resolution, may result in a better integration of ICP-MS in proteomics workflows. 


\section{Consolidation of ICP-MS in standards certification}

Species-independent ICP-MS signal response of any heteroatom present in a protein has been

long acknowledged as a great asset for the simple and direct certification of SIL peptide and protein standards [3] required in most MS-based absolute quantitate proteomics (i.e., AQUA). Nonetheless, availability of proper characterized standards is not often feasible, and it is required to synthesize and certify those standards. However, traditional certification procedures make use of multi-step, cumbersome and prone to error strategies, mostly based on amino acid analysis. By contrast, ICPMS features enable to determine with high-quality the heteroatom quantity present in the proteic species through calibrations using pure inorganic or organic compounds as single generic standard. This high analytical quality certification is worth remarking, because quality-assurance of the standards is one of the main requirements (and limitations) in any quantification strategy, especially if absolute, and it determines reliability and robustness of the experimental results.

It is significant to stress that this certification could traditionally only be addressed so far in those peptides or proteins that contained typical ICP-MS-detectable elements, such as metals, phosphorous, or selenium. The possibility to detect sulfur with high sensitivity opened the application field enormously to the certification of any protein or S-containing peptide with generic standards. Moreover, use of coupled LC separation with ICP-MS detection enables accurate and precise certification (in mass purity) of proteins even when there are impurities in the sample, or in simple mixtures of proteins. That is, it is possible to address certification of few proteins present in a mixture in just a single analysis and using a single inorganic compound as quantification (certification) standard [38]. This could be particularly relevant in cases such as the purity certification of antibodies in pharmaceutical preparations.

\section{ICP-MS as immunoassays detector: size (nano) matters}

Despite the preponderance of MS in proteomics, still many protein quantitative workflows involve immunoassays, given their high specificity, selectivity and throughput. In the last years, ICPMS has turned up as an attractive detector in immunoassays, offering good sensitivity and overcoming some limitations (e.g., matrix effects and signal overlap) of traditional luminescence detection techniques [43-45]. Typical workflow consists on the use of a protein-specific antibody tagged with a label that contains an ICP-detectable element. It is true that all these strategies are likewise limited by the immunoassay procedure, but they are benefited by the sensitive ICP-MS detection and multiplexing capabilities, which can be easily carried out using antibodies labeled with different elements, and isotopes (Figure 1). 
One of the most prominent consequences of this integrative strategy has been the development of mass cytometry technology, as result of the combination of flow cytometry with ICP-MS detection $[46,47]$. As in regular flow cytometry, several cellular components in the sample are labeled, and measured at the single cell level. However, in contrast to regular flow cytometry, tags are not fluorophores but different elemental isotopes detectable by ICP-MS. Thus, the use of antibodies labeled with different elemental isotopes as tags opens the door to address the simultaneous quantification of tens of cellular features and parameters by targeting individual proteins (and/or other cellular components). This is extremely useful for the study of cellular behavior, networks, organization, etc. overcoming spectral overlap issues with fluorophore reporters typically used in flow cytometry, at single-cell resolution [48]. High sampling resolution and quasi-simultaneous detection of a wide range of $\mathrm{m} / \mathrm{z}$ values accomplished with ICP-ToF instrumentation are the key features. The price to be paid is a worse sensitivity in comparison to quadrupole or high resolution ICP instrumentation [49]. In fact, relevance and potential of this strategy has resulted in the development of specialized ICP-ToF instruments for this application [50], and instrumental upgrades and developments are being carried out in order to provide more robust and sensitive technology $[48,49]$.

Most common tags in these strategies have been lanthanide polymeric complexes, which have a fixed element:tag ratio and provide great sensitivity, besides multiplex capabilities [51,52]. However, it has been the latest developments in nanotechnology which have greatly boosted this kind of application [53]. The use of inorganic nano-sized particles (NPs) as labels has implied a significant upgrade, overcoming stereochemical limitations of La-polymers, aside from providing high sensitivity (because NPs might contain hundreds to thousands of atoms, resulting in an amplified ICP-MS signal). Moreover, deposition of atoms over the NP, which may act as seed, results in ultraamplified signal that has led, for instance, to the highly sensitive (low attog/mL protein) detection of protein cancer biomarkers in serum [54]. The great challenge of this kind of labels though is the accurate determination of composition and ratio between NPs and antibodies, which has required the development of analytical strategies for their proper characterization [55]. Then, once the ratio element:NP:antibody:protein is accurately known, protein quantification from the elemental signal can be carried out.

The different kinds and natures of NPs used have resulted in significant applications in life science and proteomics given their different analytical characteristics. Some of them have magnetic or luminescence properties (e.g., phosphorescence NPs), and for instance they can result suitable as alternative contrast reagents [56]. The interest and impact of potential applications, together with the 
myriad of NPs, suggest further developments towards higher-performance and fit-for-purpose NPs with more and better applicability.

\section{Imaging possibilities using LA-ICP-MS}

A highly promising approach nowadays consists on the coupling of a laser-ablation system to the ICP-MS, in order to carry out imaging in solid samples, such as single cells, or biological tissues, among others (Figure 1) [53,57]. The most extended application of this technique is the mapping of the spatial distribution of a certain element of interest (e.g., $\mathrm{Cu}, \mathrm{Zn}, \mathrm{Fe}$ ), which can be used to bioimaging of cells or tissues (e.g., the distribution of metallic elements present in metalloproteins) [58] with adequate resolution $(1-10 \mu \mathrm{m})$. This methodology has a clear limitation: the element mapping does not imply per se protein mapping since it just shows elemental distribution in the sample. Besides, that signal can correspond to more than one protein that carry the element or even nonproteinaceous complexes of such element. Therefore, combination with MALDI-MS analysis is mandatory in order to identify the protein and corroborate whether the metal element is indeed bonded (coordinated) to it [59].

Alternatively, this LA-ICP-MS detection can be combined with elemental labeling, when the sample (e.g., tissue) is incubated with an antibody that holds an elemental label, as described before. The use of these antibodies provide the specificity lacked by ICP-MS when several proteins are together in the same ablated area, and its spatial distribution mapping can be performed through the detection of the element from the antibody tag. As previously commented, the possibility of using different elements and isotopes enables multiplexing capabilities. Actually, this kind of strategy has been clearly benefited from the developments in NPs labeling. Naturally, if the ratio element:tag:antibody is known, the elemental signal can be easily translated into protein concentration using non-specific standards without resorting to immunoassays calibration curves [60]. However, it has to be taken into consideration though that despite elemental ionization is independent from the species, the ablation efficiency is strongly dependent from the matrix, which is critical in heterogeneous samples such as biological tissues or cells. Therefore, in order to correct any bias in quantitative results caused by this effect, development of adequate standards has been necessary, such as ink printed internal standardization [61] or gelatin standards that simulate biological tissues [62].

\section{Perspective}


Last decade has brought consolidation and maturity of ICP-MS in proteomics. Instrumental developments enabling highly sensitive sulfur and multi-elemental detection for intact protein analysis, and the more consistent combination of ICP and ESI analysis might finally lead to the longawaited integration of ICP-MS in proteomics platforms. This might particularly apply in the case of the highly interesting intact protein analysis and top-down strategies currently ascendant in proteomics. Nevertheless, despite great progress in pre-ICP-MS separation, it still constrains quantitative capabilities and further ICP-MS implementation since full chromatographic resolution is far from being achieved in complex samples analysis. In this regard, potential improvements e.g., better packaging or multi-dimensional separations will likely help filling this gap.

Specificity of immunoassays combined with ICP-MS detection offer great and unique possibilities in proteomics, especially since the integration of nanotechnology developments by using nanoparticles, which proved excellent elemental labels offering high sensitivity and versatile applications. Moreover, the great efforts made so far and existent room for further developments in this regard suggest that potential possibilities of this kind of strategy can establish a significant upgrade in immunohistochemistry-based proteomics.

\section{Acknowledgements}

Authors acknowledge support by Spanish Ministry of Economy and Competitiveness through CTQ2016-79412-P and BES-2014-068032 (F.C.C).

\section{References}

[1] J. Bettmer, M. Montes Bayón, J. Ruiz Encinar, M.L. Fernández Sánchez, M. del R. Fernández de la Campa, A. Sanz Medel, The emerging role of ICP-MS in proteomic analysis, J. Proteomics. 72 (2009) 989-1005. doi:10.1016/j.jprot.2009.05.003.

[2] E. Svantesson, J. Pettersson, K.E. Markides, The use of inorganic elemental standards in the quantification of proteins and biomolecular compounds by inductively coupled plasma spectrometry, J. Anal. At. Spectrom. 17 (2002) 491-496. doi:10.1039/b200072p.

[3] F. Calderón-Celis, J. Ruiz Encinar, A. Sanz-Medel, Standardization approaches in absolute quantitative proteomics with mass spectrometry, Mass Spectrom. Rev. (2017) 1-23. doi:10.1002/mas.21542.

[4] M. Wind, W.D. Lehmann, Element and molecular mass spectrometry — an emerging analytical dream team in the life sciences, J. Anal. At. Spectrom. 19 (2004) 20-25. doi:10.1039/B309482K.

[5] D. Schaumlöffel, A. Prange, A new interface for combining capillary electrophoresis with inductively coupled plasma-mass spectrometry, Fresenius. J. Anal. Chem. 364 (1999) 452-456. doi:10.1007/s002160051366.

[6] D. Schaumlöffel, J. Ruiz Encinar, R. Łobiński, Development of a Sheathless Interface between Reversed-Phase 
Capillary HPLC and ICPMS via a Microflow Total Consumption Nebulizer for Selenopeptide Mapping, Anal. Chem. 75 (2003) 6837-6842. doi:10.1021/ac034819h.

[7] M. Wind, M. Edler, N. Jakubowski, M. Linscheid, H. Wesch, W.D. Lehmann, Analysis of Protein Phosphorylation by Capillary Liquid Chromatography Coupled to Element Mass Spectrometry with $31 \mathrm{P}$ Detection and to Electrospray Mass Spectrometry, Anal. Chem. 73 (2001) 29-35. doi:10.1021/ac0009595.

[8] A. Leclercq, A. Nonell, J.L. Todolí Torró, C. Bresson, L. Vio, T. Vercouter, F. Chartier, Introduction of organic/hydro-organic matrices in inductively coupled plasma optical emission spectrometry and mass spectrometry: A tutorial review. Part I. Theoretical considerations, Anal. Chim. Acta. 885 (2015) 33-56. doi:10.1016/j.aca.2015.03.049.

[9] J. Szpunar, Bio-inorganic speciation analysis by hyphenated techniques, Analyst. 125 (2000) 963-988. doi:10.1039/a909137h.

[10] A. Sanz-Medel, "Heteroatom-tagged" quantification of proteins via ICP-MS, Anal. Bioanal. Chem. 408 (2016) 5393-5395. doi:10.1007/s00216-016-9687-5.

[11] J. Szpunar, Advances in analytical methodology for bioinorganic speciation analysis: metallomics, metalloproteomics and heteroatom-tagged proteomics and metabolomics, Analyst. 130 (2005) 442. doi: $10.1039 / \mathrm{b} 418265 \mathrm{k}$.

[12] A. Sanz-Medel, M. Montes-Bayón, M.L. Fernández-Sánchez, Trace element speciation by ICP-MS in large biomolecules and its potential for proteomics, Anal. Bioanal. Chem. 377 (2003) 236-247. doi:10.1007/s00216003-2082-z.

[13] K. Połeć-Pawlak, D. Schaumlöffel, J. Szpunar, A. Prange, R. Łobiński, Analysis for metal complexes with metallothionein in rat liver by capillary zone electrophoresis using ICP double-focussing sector-field isotope dilution MS and electrospray MS detection, J. Anal. At. Spectrom. 17 (2002) 908-912. doi:10.1039/B110579P.

[14] Ò. Palacios, J.R. Encinar, G. Bertin, R. Lobinski, Analysis of the selenium species distribution in cow blood by size exclusion liquid chromatography-inductively coupled plasma collision cell mass spectrometry (SECICPccMS), Anal. Bioanal. Chem. 383 (2005) 516-522. doi:10.1007/s00216-005-0015-8.

[15] Ò. Palacios, J. Ruiz Encinar, D. Schaumlöffel, R. Lobinski, Fractionation of selenium-containing proteins in serum by multiaffinity liquid chromatography before size-exclusion chromatography-ICPMS, Anal. Bioanal. Chem. 384 (2006) 1276-1283. doi:10.1007/s00216-005-0286-0.

[16] A. Sarmiento-González, J. Ruiz Encinar, A.M. Cantarero-Roldán, J.M. Marchante-Gayón, A. Sanz-Medel, HPLC-ICPMS and Stable Isotope-Labeled Approaches To Assess Quantitatively Ti(IV) Uptake by Transferrin in Human Blood Serum, Anal. Chem. 80 (2008) 8702-8711. doi:10.1021/ac801029p.

[17] V. Van Lierde, C.C. Chéry, K. Strijckmans, M. Galleni, B. Devreese, J. Van Beeumen, L. Moens, F. Vanhaecke, Capillary electrophoresis hyphenated to inductively coupled plasma-sector field-mass spectrometry for the stoichiometric determination of $\mathrm{Zn}$ bound to Aeromonas hydrophila Zn beta-lactamase, J. Anal. At. Spectrom. 19 (2004) 888-893. doi:10.1039/B400962B.

[18] J. Villanueva, M. Carrascal, J. Abian, Isotope dilution mass spectrometry for absolute quantification in 
proteomics: Concepts and strategies, J. Proteomics. 96 (2014) 184-199. doi:10.1016/j.jprot.2013.11.004.

[19] P. Rodríguez-González, J.M. Marchante-Gayón, J.I. García Alonso, A. Sanz-Medel, Isotope dilution analysis for elemental speciation: a tutorial review, Spectrochim. Acta Part B At. Spectrosc. 60 (2005) 151-207. doi:10.1016/j.sab.2005.01.005.

[20] H. Zhang, W. Yan, R. Aebersold, Chemical probes and tandem mass spectrometry: a strategy for the quantitative analysis of proteomes and subproteomes, Curr. Opin. Chem. Biol. 8 (2004) 66-75. doi:10.1016/j.cbpa.2003.12.001.

[21] M. Wind, H. Wesch, W.D. Lehmann, Protein Phosphorylation Degree: Determination by Capillary Liquid Chromatography and Inductively Coupled Plasma Mass Spectrometry, Anal. Chem. 73 (2001) 3006-3010. doi:10.1021/ac010066s.

[22] A. Pereira Navaza, J. Ruiz Encinar, A. Sanz-Medel, Absolute and Accurate Quantification of Protein Phosphorylation by Using an Elemental Phosphorus Standard and Element Mass Spectrometry, Angew. Chemie Int. Ed. 46 (2007) 569-571. doi:10.1002/anie.200602517.

[23] D. Pröfrock, A. Prange, Compensation of gradient related effects when using capillary liquid chromatography and inductively coupled plasma mass spectrometry for the absolute quantification of phosphorylated peptides, J. Chromatogr. A. 1216 (2009) 6706-6715. doi:10.1016/j.chroma.2009.08.002.

[24] A. Helfrich, J. Bettmer, Determination of phosphorylation degrees in caseins by on-line gel electrophoresis coupled to ICP-SFMS, J. Anal. At. Spectrom. 22 (2007) 1296. doi:10.1039/b706226e.

[25] A. Pereira Navaza, J. Ruiz Encinar, A. Sanz-Medel, Element mass spectrometry as a tool for high-resolution temporal dynamics investigations of peptide phosphorylation, Chem. Commun. (2008) 6230. doi:10.1039/b811934a.

[26] A. Pereira Navaza, J. Ruiz Encinar, M. Carrascal, J. Abián, A. Sanz-Medel, Absolute and Site-Specific Quantification of Protein Phosphorylation Using Integrated Elemental and Molecular Mass Spectrometry: Its Potential To Assess Phosphopeptide Enrichment Procedures, Anal. Chem. 80 (2008) 1777-1787. doi:10.1021/ac7022316.

[27] B. Eyrich, A. Sickmann, R.P. Zahedi, Catch me if you can: Mass spectrometry-based phosphoproteomics and quantification strategies, Proteomics. 11 (2011) 554-570. doi:10.1002/pmic.201000489.

[28] P. Giusti, D. Schaumlöffel, J. Ruiz Encinar, J. Szpunar, Interfacing reversed-phase nanoHPLC with ICP-MS and on-line isotope dilution analysis for the accurate quantification of selenium-containing peptides in protein tryptic digests, J. Anal. At. Spectrom. 20 (2005) 1101. doi:10.1039/b506620d.

[29] M. Xu, L. Yang, Q. Wang, Quantification of selenium-tagged proteins in human plasma using species-unspecific isotope dilution ICP-DRC-qMS coupled on-line with anion exchange chromatography, J. Anal. At. Spectrom. 23 (2008) 1545. doi:10.1039/b804935a.

[30] C. Rappel, D. Schaumlöffel, The role of sulfur and sulfur isotope dilution analysis in quantitative protein analysis, Anal. Bioanal. Chem. 390 (2008) 605-615. doi:10.1007/s00216-007-1607-2.

[31] M. Wind, A. Wegener, A. Eisenmenger, R. Kellner, W.D. Lehmann, Sulfur as the Key Element for Quantitative 
Protein Analysis by Capillary Liquid Chromatography Coupled to Element Mass Spectrometry, Angew. Chemie Int. Ed. 42 (2003) 3425-3427. doi:10.1002/anie.200250547.

[32] S. El Balkhi, J. Poupon, J.-M. Trocello, F. Massicot, F. Woimant, O. Laprévote, Human Plasma Copper Proteins Speciation by Size Exclusion Chromatography Coupled to Inductively Coupled Plasma Mass Spectrometry. Solutions for Columns Calibration by Sulfur Detection, Anal. Chem. 82 (2010) 6904-6910. doi:10.1021/ac101128x.

[33] A. Pereira Navaza, J.R. Encinar, A. Ballesteros, J.M. González, A. Sanz-Medel, Capillary HPLC-ICPMS and Tyrosine Iodination for the Absolute Quantification of Peptides Using Generic Standards, Anal. Chem. 81 (2009) 5390-5399. doi:10.1021/ac9005606.

[34] C. Rappel, D. Schaumlöffel, Absolute Peptide Quantification by Lutetium Labeling and NanoHPLC-ICPMS with Isotope Dilution Analysis, Anal. Chem. 81 (2009) 385-393. doi:10.1021/ac801814a.

[35] N. Tang, Z. Li, L. Yang, Q. Wang, ICPMS-Based Specific Quantification of Phosphotyrosine: A GalliumTagging and Tyrosine-Phosphatase Mediated Strategy, Anal. Chem. 88 (2016) 9890-9896. doi:10.1021/acs.analchem.6b02979.

[36] S. Diez Fernández, N. Sugishama, J. Ruiz Encinar, A. Sanz-Medel, Triple Quad ICPMS (ICPQQQ) as a New Tool for Absolute Quantitative Proteomics and Phosphoproteomics, Anal. Chem. 84 (2012) 5851-5857. doi:10.1021/ac3009516.

[37] E. Bolea-Fernandez, L. Balcaen, M. Resano, F. Vanhaecke, Overcoming spectral overlap via inductively coupled plasma-tandem mass spectrometry (ICP-MS/MS). A tutorial review, J. Anal. At. Spectrom. 32 (2017) 16601679. doi:10.1039/C7JA00010C.

[38] F. Calderón-Celis, S. Diez-Fernández, J.M. Costa-Fernández, J. Ruiz Encinar, J.J. Calvete, A. Sanz-Medel, Elemental Mass Spectrometry for Absolute Intact Protein Quantification without Protein-Specific Standards: Application to Snake Venomics, Anal. Chem. 88 (2016) 9699-9706. doi:10.1021/acs.analchem.6b02585.

[39] V. González-Ruiz, A.I. Olives, M.A. Martín, Core-shell particles lead the way to renewing high-performance liquid chromatography, TrAC Trends Anal. Chem. 64 (2015) 17-28. doi:10.1016/j.trac.2014.08.008.

[40] F. Calderón-Celis, L. Cid-Barrio, J. Ruiz Encinar, A. Sanz-Medel, J.J. Calvete, Absolute venomics: Absolute quantification of intact venom proteins through elemental mass spectrometry, J. Proteomics. 164 (2017) $33-42$. doi:10.1016/j.jprot.2017.06.001.

[41] F. Calderón-Celis, A. Sanz-Medel, J.R. Encinar, Universal absolute quantification of biomolecules using element mass spectrometry and generic standards, Chem. Commun. 54 (2018) 904-907. doi:10.1039/C7CC09059E.

[42] S. Shen, X.-F. Li, W.R. Cullen, M. Weinfeld, X.C. Le, Arsenic Binding to Proteins, Chem. Rev. 113 (2013) 7769-7792. doi:10.1021/cr300015c.

[43] A.R. Montoro Bustos, L. Trapiella-Alfonso, J. Ruiz Encinar, J.M. Costa-Fernández, R. Pereiro, A. Sanz-Medel, Elemental and molecular detection for Quantum Dots-based immunoassays: A critical appraisal, Biosens. Bioelectron. 33 (2012) 165-171. doi:10.1016/j.bios.2011.12.046.

[44] M. Wang, W.-Y. Feng, Y.-L. Zhao, Z.-F. Chai, ICP-MS-Based strategies for protein quantification, Mass 
Spectrom. Rev. 29 (2010) 326-348. doi:10.1002/mas.20241.

[45] E. Razumienko, O. Ornatsky, R. Kinach, M. Milyavsky, E. Lechman, V. Baranov, M.A. Winnik, S.D. Tanner, Element-tagged immunoassay with ICP-MS detection: Evaluation and comparison to conventional immunoassays, J. Immunol. Methods. 336 (2008) 56-63. doi:10.1016/j.jim.2008.03.011.

[46] D.R. Bandura, V.I. Baranov, O.I. Ornatsky, A. Antonov, R. Kinach, X. Lou, S. Pavlov, S. Vorobiev, J.E. Dick, S.D. Tanner, Mass Cytometry: Technique for Real Time Single Cell Multitarget Immunoassay Based on Inductively Coupled Plasma Time-of-Flight Mass Spectrometry, Anal. Chem. 81 (2009) 6813-6822. doi:10.1021/ac901049w.

[47] S.C. Bendall, E.F. Simonds, P. Qiu, E.-A.D. Amir, P.O. Krutzik, R. Finck, R. V Bruggner, R. Melamed, A. Trejo, O.I. Ornatsky, R.S. Balderas, S.K. Plevritis, K. Sachs, D. Pe’er, S.D. Tanner, G.P. Nolan, Single-Cell Mass Cytometry of Differential Immune and Drug Responses Across a Human Hematopoietic Continuum, Science (80-. ). 332 (2011) 687-696. doi:10.1126/science.1198704.

[48] M.H. Spitzer, G.P. Nolan, Mass Cytometry: Single Cells, Many Features, Cell. 165 (2016) $780-791$. doi:10.1016/j.cell.2016.04.019.

[49] S. Miyashita, S. Fujii, K. Shigeta, K. Inagaki, Single Cell Analysis by Using ICP-MS, in: Metallomics, Springer Japan, Tokyo, 2017: pp. 107-124. doi:10.1007/978-4-431-56463-8_5.

[50] S.D. Tanner, D.R. Bandura, O. Ornatsky, V.I. Baranov, M. Nitz, M.A. Winnik, Flow cytometer with mass spectrometer detection for massively multiplexed single-cell biomarker assay, Pure Appl. Chem. 80 (2008) 2627-2641. doi:10.1351/pac200880122627.

[51] X. Lou, G. Zhang, I. Herrera, R. Kinach, O. Ornatsky, V. Baranov, M. Nitz, M.A. Winnik, Polymer-Based Elemental Tags for Sensitive Bioassays, Angew. Chemie Int. Ed. 46 (2007) 6111-6114. doi:10.1002/anie.200700796.

[52] A. Tholey, D. Schaumlöffel, Metal labeling for quantitative protein and proteome analysis using inductivelycoupled plasma mass spectrometry, TrAC Trends Anal. Chem. 29 (2010) 399-408. doi:10.1016/j.trac.2010.01.010.

[53] A. Smith, H. Duan, A. Mohs, S. Nie, Bioconjugated quantum dots for in vivo molecular and cellular imaging, Adv. Drug Deliv. Rev. 60 (2008) 1226-1240. doi:10.1016/j.addr.2008.03.015.

[54] M. Garcia-Cortes, J. Ruiz Encinar, J.M. Costa-Fernandez, A. Sanz-Medel, Highly sensitive nanoparticle-based immunoassays with elemental detection: Application to Prostate-Specific Antigen quantification, Biosens. Bioelectron. 85 (2016) 128-134. doi:10.1016/j.bios.2016.04.090.

[55] J.M. Costa-Fernández, M. Menéndez-Miranda, D. Bouzas-Ramos, J.R. Encinar, A. Sanz-Medel, Mass spectrometry for the characterization and quantification of engineered inorganic nanoparticles, TrAC Trends Anal. Chem. 84 (2016) 139-148. doi:10.1016/j.trac.2016.06.001.

[56] E.C. Cho, C. Glaus, J. Chen, M.J. Welch, Y. Xia, Inorganic nanoparticle-based contrast agents for molecular imaging, Trends Mol. Med. 16 (2010) 561-573. doi:10.1016/j.molmed.2010.09.004.

[57] C. Giesen, L. Waentig, T. Mairinger, D. Drescher, J. Kneipp, P.H. Roos, U. Panne, N. Jakubowski, Iodine as an 
elemental marker for imaging of single cells and tissue sections by laser ablation inductively coupled plasma mass spectrometry, J. Anal. At. Spectrom. 26 (2011) 2160. doi:10.1039/c1ja10227c.

[58] J.S. Becker, A. Matusch, B. Wu, Bioimaging mass spectrometry of trace elements - recent advance and applications of LA-ICP-MS: A review, Anal. Chim. Acta. 835 (2014) 1-18. doi:10.1016/j.aca.2014.04.048.

[59] L. Cid-Barrio, F. Calderón-Celis, P. Abásolo-Linares, M.L. Fernández-Sánchez, J.M. Costa-Fernández, J.R. Encinar, A. Sanz-Medel, Advances in absolute protein quantification and quantitative protein mapping using ICP-MS, TrAC Trends Anal. Chem. 104 (2018) 148-159. doi:10.1016/j.trac.2017.09.024.

[60] M. Cruz-Alonso, B. Fernandez, M. García, H. González-Iglesias, R. Pereiro, Quantitative Imaging of Specific Proteins in the Human Retina by Laser Ablation ICPMS using Bioconjugated Metal Nanoclusters as Labels, Anal. Chem. 90 (2018) 12145-12151. doi:10.1021/acs.analchem.8b03124.

[61] S. Hoesl, B. Neumann, S. Techritz, G. Sauter, R. Simon, H. Schlüter, M. W. Linscheid, F. Theuring, N. Jakubowski, L. Mueller, Internal standardization of LA-ICP-MS immuno imaging via printing of universal metal spiked inks onto tissue sections, J. Anal. At. Spectrom. 31 (2016) 801-808. doi:10.1039/C5JA00409H.

[62] D. Gholap, J. Verhulst, W. Ceelen, F. Vanhaecke, Use of pneumatic nebulization and laser ablation-inductively coupled plasma-mass spectrometry to study the distribution and bioavailability of an intraperitoneally administered Pt-containing chemotherapeutic drug, Anal. Bioanal. Chem. 402 (2012) 2121-2129. doi:10.1007/s00216-011-5654-3. 


\section{LEGENDS OF FIGURES}

Figure 1. Possibilities in proteomics analysis of real sample using ICP-MS.

Figure 2. Comparison of advantages, requirements and disadvantages in S-based absolute protein quantification with ICP-MS, at the intact protein and the peptide levels.

\section{Figure 1}

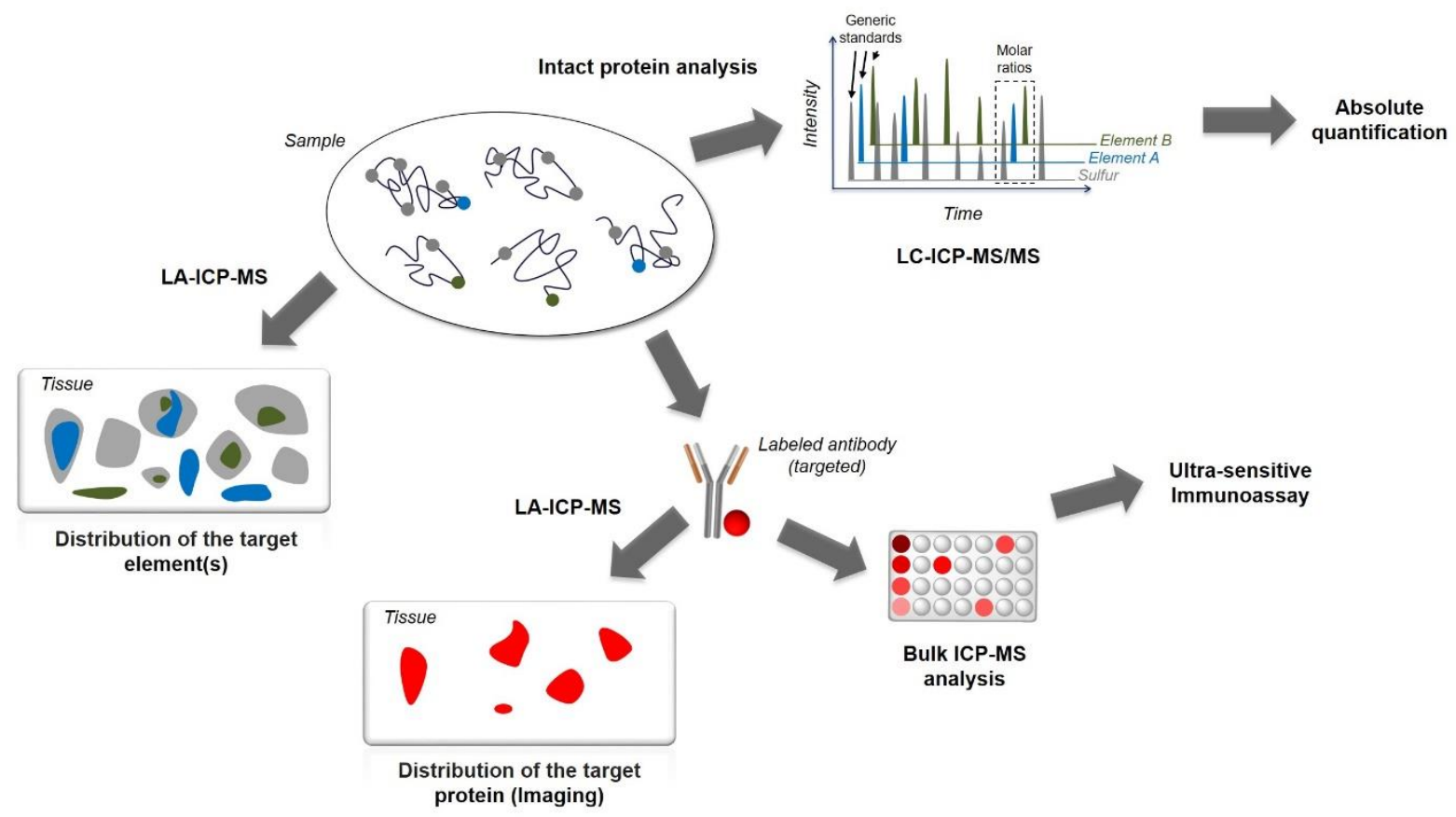

Figure 2

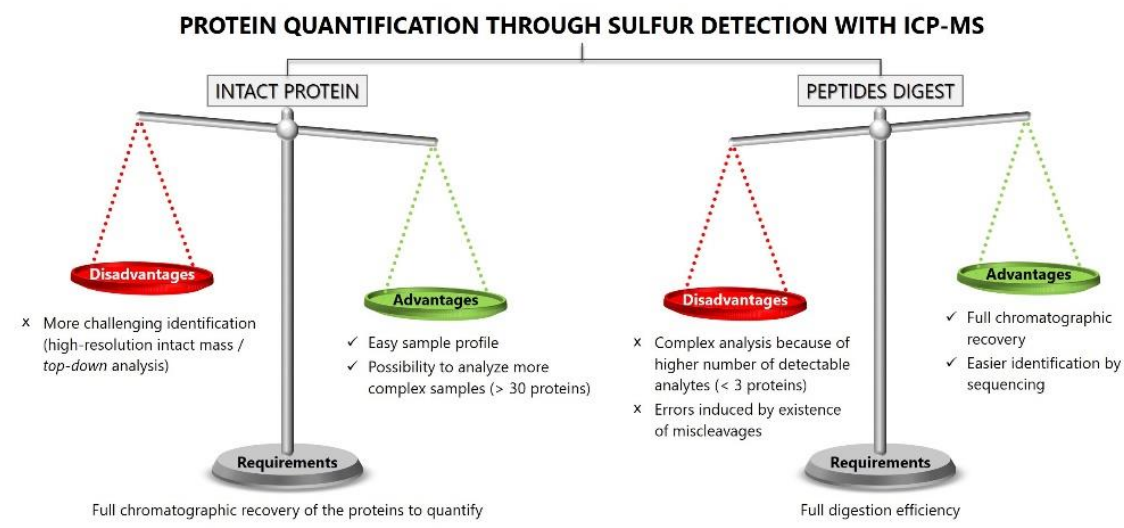

